\title{
A QUALIDADE DOS SERVIÇOS CONTÁBEIS COMO FERRAMENTA DE GESTÃO PARA OS ESCRITÓRIOS DE CONTABILIDADE
}

\author{
Tânia Regina Zunino Shigunov \& André Rogério Shigunov \\ BACHAREL DE CIÊNCIAS CONTÁBEIS PELA UNIVERSIDADE FEDERAL DE \\ SANTA CATARINA
}

\author{
E-MAIL: TANISHIG@ZIPMAIL.COM.BR
}

\begin{abstract}
RESUMO
Sobreviver num mercado competitivo representa o grande desafio das empresas nos dias de hoje, justificando assim corresponder às necessidades e expectativas dos clientes. $O$ presente trabalho tem como tema a qualidade na prestação de serviços contábeis como ferramenta de gestão, procurando munir o escritório de condições que atendam às exigências dos clientes.

A contabilidade deixou de ser apenas a escrituração das mutações do patrimônio, passando a ser usada como um instrumento de gestão para o planejamento, controle e tomada de decisões.

A contabilidade afim de acompanhar o desenvolvimento das empresas e abertura dos mercados, passou a se preocupar com a questão da qualidade das informações, permitindo aos usuários acompanhar e avaliar a evolução das empresas através da correta aplicação das normas brasileiras de contabilidade e princípios fundamentais de contabilidade como meio para atingir estes fins.

Com o advento da tecnologia da informação, permite-se que o contador ofereça excelência nos serviços prestados, pois através das informações contábeis pode fazer parte ativamente do processo decisório das empresas.

Adotar a gestão pela qualidade dentro de uma organização contábil significa passar por mudanças significativas, adotar a qualidade através do programa 5 " $S$ " e o ciclo PDCA, cria-se um ambiente de trabalho dinâmico, estimulando trabalho em equipe, motivando os funcionários, atendendo às necessidades dos clientes e tornando a empresa cada vez mais competitiva.
\end{abstract}

\section{1-INTRODUÇÃO}

A qualidade é reconhecida como fator decisivo para a escolha do consumidor (cliente). As empresas para competirem devem adaptar-se permanentemente as mudanças das necessidades dos clientes, pois as mesmas bem sucedidas tem sido aquelas que reconhecem as mudanças à sua volta e adotam medidas adequadas para compensar as ameaças produzidas por essas mudanças. O aumento da competitividade produzirá sem dúvida a sobrevivência dos mais qualificados.

Devido o grande número de profissionais atuantes na área de serviços contábeis, o mercado está cada vez mais competitivo, a concorrência vem se tornando um fator preocupante, tornando necessário que o contador seja um componente ativo na gestão interna, visando a qualidade, custo, atendimento e inovação na prestação de serviços aos clientes.

Dentro do contexto atual esses fatores revelam-se críticos para a sobrevivência dos escritórios de Contabilidade, pois cada vez mais eles se 
preocupam com a concorrência de preços do que, muitas vezes, com a qualidade dos serviços prestados propriamente ditos.

O investimento em qualidade nos serviços contábeis revela-se determinante para a busca da excelência organizacional. Os clientes estão cada vez mais exigentes, por sua vez é preciso que os contadores adotem práticas eficazes de gestão, afim de preservar e obter novos clientes.

O donos de escritórios de contabilidade devem-se ater, também, ao enfoque gerencial de seu escritório, centrado na qualidade e baseado na participação de seus colaboradores, com o objetivo de alcançar e manter a lucratividade através da satisfação e dos benefícios para os clientes, colaboradores e para a sociedade.

Dentre tantas exigências que o contador deve procurar seguir para atender as exigências do mercado destaca-se fundamentalmente, que ele siga os princípios fundamentais e as normas brasileiras de contabilidade dentro de suas práticas contábeis e sem dúvida, manter sua conduta voltada ao código de ética profissional do contabilista.

Conforme NASH apud ABICALAFFE (199_, 8) "quanto mais alta a qualidade, mais fácil é fazer negócios de forma ética... (...) $E$ inversamente,quanto maior sua ética, mais fácil é adotar e implementar uma estratégia de qualidade".

A sobrevivência das empresas prestadoras de serviços contábeis depende principalmente da dedicação, da competência administrativa, da excelência e da diferenciação do serviço oferecido. Cabe a cada escritório contábil conhecer sua capacidade de serviço e com que qualidade este serviço chegam ao cliente, tornando-se possível atingir de forma gradual a excelência nos serviços prestados ampliando dessa maneira suas possibilidades, pois com a satisfação dos clientes torna-se possível a indicação de novos clientes e assim sucessivamente. Diante do exposto, verifica-se que a qualidade é de grande importância, e tem ampla relação com os serviços prestados.

O presente estudo tem por tema a qualidade nos serviços contábeis, procurando verificar quais as ações promovidas pelos escritórios de contabilidade para a busca da melhoria no atendimento aos clientes e a expectativa dos clientes em relação a qualidade dos serviços prestados.

\section{2-A CONTABILIDADE E SEUS OBJETIVOS}

A Contabilidade como nos demais ramos da ciência possui seu objeto próprio, o "patrimônio da empresa." Na contabilidade identifica-se a situação do patrimônio através da mensuração, análise e registros dos fatos contábeis que alteram ou não o patrimônio.

De acordo com a Resolução do Conselho Federal de Contabilidade - CFC n. ${ }^{\circ} 785$, de 28 julho de 1995, em seu inciso 1.1.1:

A contabilidade, na sua condição de ciência social, cujo objeto é o Patrimônio, busca, por meio da apreensão, da quantificação, do registro, da eventual sumarização, da demonstração, da análise e relato das mutações sofridas pelo patrimônio da Entidade particularizada, a geração de informações quantitativas e qualitativas sobre ela, expressas tanto em termos físicos quanto monetários.

O conhecimento que a contabilidade tem de seu objeto está em constante movimento, tendo em vista que os acontecimentos no contexto sócio-político e econômico, estão constantemente em modificação.

Segundo FRANCO (1983, p.19), "O objeto da contabilidade é pois o patrimônio, e em torno dele se desenvolvem suas funções, como meio para atingir sua finalidade". 
A contabilidade tem como objetivo (Finalidade) principal prestar informação aos usuários através do acompanhamento do Patrimônio das entidades, o meio para atingir este objetivo é através da correta aplicação dos princípios e características qualitativas da informação contábil, bem como a causa de suas variações.

Para IUDíCIBUS ( 1997, p. 23 ): "o objetivo básico da Contabilidade, portanto, pode ser resumido no fornecimento de informações econômicas para vários usuários, de forma que propiciem decisões racionais".

Segundo HENDRICKSEN apud IUDÍCIBUS (1997, p. 22) "o objetivo da Contabilidade é fornecer um conjunto de relatórios financeiros para usuários indeterminados com relação a riqueza ou transações econômicas da empresa...".

Estas informações serão evidenciadas aos usuários, podendo ser definidos como qualquer pessoa física ou jurídica que tenha interesse na situação de determinada entidade. Podendo ser divididos como usuários internos e externos à organização.

Conforme tabela abaixo identificam-se os principais usuários da informação contábil, juntamente com o tipo de informação para cada tipo de usuário.

Tabela 1 - Usuários da Informação Contábil

Usuário da Informação Contábil

Meta que desejaria maximizar ou tipo de informação mais importante

- Acionista Minoritário

Fluxo regular de dividendos.

- Acionista majoritário

ou com grande participação

Fluxo de dividendos, valor de mercado da ação, lucro por ação.

- Acionista preferencial

Fluxo de dividendos mínimos ou fixos.

- Emprestadores em geral

Geração de fluxo de caixa futuros suficientes para receber de volta 0 capital mais os juros, com segurança.

- Entidades governamentais

Valor adicionado, produtividade, lucro tributável.

- Empregados em geral, como assalariados Fluxo de caixa futuro capaz de assegurar bons aumentos ou manutenção de salários, com segurança; liquidez.

- Média e alta administração

Retorno sobre o ativo, retorno sobre o patrimônio líquido; situação de liquidez e endividamento confortáveis.

FONTE: IUDÍCIBUS, Sérgio de. Teoria da Contabilidade, 5. ed. São Paulo, 1997. p. 21

\section{1-Usuário Interno}

Os usuários internos fazem uso das informações mais aprofundadas e específicas da entidade, aquelas relativas ao processo operacional da empresa, com isso torna-se decisiva aos administradores que contam com uma série de 
Revista Eletrônica de Ciência Administrativa (RECADM) - ISSN 1677-7387

Faculdade Cenecista de Campo Largo - Coordenação do Curso de Administração

v. 2, n. 1, maio/2003 - http://revistas.facecla.com.br/index.php/recadm/

informações adicionais que a contabilidade financeira não the proporciona. Com a contabilidade gerencial voltada para fins internos, procura suprir os gerentes de um elenco de informações para o planejamento, controle e a tomada de decisões, diferenciando-se da contabilidade financeira, pois não se prende aos princípios fundamentais de contabilidade, podendo fornecer diferentes tipos de relatórios para diferentes decisões.

De acordo com IUDÍCIBUS e MARION (1999, p. 54)

Para os usuários internos à entidade, interessam além das demonstrações Contábeis como ponto de partida, também subsidiam os tomadores internos de decisão, outros tipos de relatórios que aliem conceitos e informações derivantes do sistema de Contabilidade financeira(Geral) - que produz os relatórios tradicionais, a outros derivantes da Contabilidade de Custos, da administração financeira, da administração da produção e outras disciplinas que apresentam conceitos importantes para a tomada de decisões.

A contabilidade gerencial serve como um instrumento de gestão que auxilia na tomada de decisões, pois ela flexibiliza a informação de acordo com a necessidade que cada gestor tenha, e fornece subsídios para as decisões corretas, sendo vitais para a continuidade da empresa.

\section{2- Usuário Externo}

Os usuários externos concentram-se principalmente nas demonstrações contábeis publicadas, e se utilizam das informações extraídas da contabilidade financeira.

Conforme IUDICÍBUS e MARION (1999, p. 44) "O usuário externo se prende mais a contabilidade financeira como contabilidade geral, necessária a todas as empresas. Ela fornece informações básicas aos usuários e é obrigatória conforme a legislação comercial".

Para seus usuários Externos, conforme a Lei 6.404/76 apud MARION (1994): A Lei das Sociedades por Ações estabelece que ao fim de cada exercício social a entidade deva elaborar de acordo com os princípios de contabilidade as seguintes demonstrações contábeis:

Balanço Patrimonial;

Demonstrações do Resultado do Exercício;

Demonstrações de lucros e Prejuízos Acumulados ou Demonstrações das Mutações do Patrimônio Líquido;

Demonstrações de Origens e Aplicações de Recursos.

Essas informações fornecidas pela contabilidade são determinantes, seja para acionistas, administradores ou gerentes, como, também, para o "fisco", bancos, fornecedores, investidores e sociedade em geral.

A contabilidade como sistema de informação deve estar apta a atender as necessidades de seus usuários, pois é através da contabilidade que os usuários obtém as informações capacitando-os a planejar, controlar e fundamentar sua tomada de decisão. Sendo assim, deve estar revestida de uma série de características e atributos.

\section{3-CARACTERÍSTICAS QUALITATIVAS DA INFORMAÇÃO CONTÁBIL}

Nos primórdios da humanidade a contabilidade era usada para medir e avaliar a evolução do patrimônio das entidades, mesmo nos tempos mais remotos quando surgiram as primeiras organizações econômicas, o conhecimento prático e as diferentes formas de informação auxiliavam o homem nas suas atividades. 
Revista Eletrônica de Ciência Administrativa (RECADM) - ISSN 1677-7387

Faculdade Cenecista de Campo Largo - Coordenação do Curso de Administração

v. 2, n. 1, maio/2003 - http://revistas.facecla.com.br/index.php/recadm/

Com o passar do tempo a contabilidade foi se aperfeiçoando, sempre em função dos novos desafios apresentados pela evolução dos usuários das empresas e o surgimento de novas necessidades de informação.

Segundo RAUPP (2000, p. 44):

Com o advento da tecnologia da informação e o processo de globalização mundial as exigências cresceram e se diversificaram. A competição global exige que as empresas estejam comprometidas com contínuo e completo aperfeiçoamento de seus produtos, processos e colaboradores. Um dos principais ativos de uma empresa são suas informações e seus recursos humanos que delas se utilizam (...) a qualidade e confiabilidade desses dados influem decisivamente no sucesso dos negócios.

Nos dias atuais a contabilidade passa por um desafio, que é a de gerar informação de qualidade em um mundo globalizado,dinâmico, e com a necessidade dessas informações em tempo hábil, hoje mais do que avaliar, a função da contabilidade é a de prestar informação para o planejamento, controle e para a tomada de decisão.

Dentro de uma organização os administradores estão constantemente tomando decisões diversas. Cabe a contabilidade estar preparada com diferentes relatórios trazendo informações oportunas, com conteúdo adequado e confiáveis, periodicamente.

De acordo com a Resolução do CFC n. ${ }^{\circ}$ 785, de 28 de julho de 1995, em seu inciso 1.1.2, "As informações geradas pela Contabilidade devem propiciar aos seus usuários base segura as suas decisões, pela compreensão do estado em que se encontra a Entidade, seu desempenho, sua evolução, riscos e oportunidades que oferece".

A informação contábil deve revelar a veracidade dos fatos contábeis, não privilegiando nenhum tipo de usuário, mas proporcionando o entendimento de todos que fazem uso dessas informações.

Segue ainda em seus incisos 1.3.1 "A informação contábil deve ser, em geral e antes de tudo veraz e eqüitativa, de forma a satisfazer as necessidades comuns a um grande número de diferentes usuários, não podendo privilegiar deliberadamente a nenhum deles, considerando o fato de que os interesses destes nem sempre são coincidentes".

De acordo com a Resolução do CFC n. ${ }^{\circ} 785$, de 28 de julho de 1995, em seu inciso 1.3.2 "A informação contábil, em especial aquela contida nas demonstrações contábeis, notadamente as previstas em legislação deve propiciar revelação suficiente sobre a Entidade, de modo a facilitar a concretização dos propósitos do usuário".

O departamento de contabilidade é uma das áreas mais importantes dentro de uma empresa, pois detém uma série de informações que fazem a mesma funcionar e crescer.

Segundo VASCONCELOS (2002, p. 25)

A informação deve ser adequada aos fins a que se destina, uma vez que facilite o entendimento do usuário, deve emergir da verdade, ser eficaz e atingir o objetivo do usuário, deve ser precisa e não conter erros, precisa ser relevante, confiável e segura para a tomada de decisão, deve ser apresentada de forma simples afim de se tornar compreensível para quem precisa dela.

A qualidade nas decisões é influenciada pela qualidade do sistema de informação, e a contabilidade como instrumento de gestão, deve oferecer aos usuários informações com determinados atributos, que a tornarão úteis para a tomada de decisão. 
Revista Eletrônica de Ciência Administrativa (RECADM) - ISSN 1677-7387

Faculdade Cenecista de Campo Largo - Coordenação do Curso de Administração

v. 2, n. 1, maio/2003 - http://revistas.facecla.com.br/index.php/recadm/

De acordo com o IASB - International Accouunting Standards Board (1998, p.35) "As características qualitativas são atributos que tornam as informações contábeis úteis para os usuários. Estes atributos. são: a confiabilidade, relevância, compreensibilidade e comparabilidade".

O Conselho Federal de Contabilidade define que as informações devam ser evidenciadas aos usuários de maneira simples, compreensiva, em tempo hábil e que satisfaça suas necessidades para a tomada de decisão, e cita que as informações contábeis devem ser revestidas dos seguintes atributos:a confiabilidade, tempestividade, compreensibilidade e comparabilidade.

\section{1-Confiabilidade}

Segundo o IASB (1998, p.36) "A informação tem a qualidade de confiabilidade quando está livre de erros relevantes, e podem os usuários depositar confiança como representando fielmente aquilo que ela diz representar ou poderia razoavelmente esperar-se que representa-se".

O IASB (1998, p36) coloca ainda como requisitos para que a informação seja confiável, que a informação tenha

Representação adequada;

Primazia da essência sobre a forma;

Neutralidade;

Prudência;

Integridade

Representação adequada: a informação para ser confiável, deve representar fielmente as transações e outros eventos da entidade. As empresas, muitas vezes, apresentam dificuldades na identificação das transações e eventos quanto à sua mensuração ou forma de apresentação.

Primazia da essência sobre a forma: Para que a informação represente fielmente as transações e eventos que ela se propõe a representar, é necessário que os mesmos sejam contabilizados e apresentados de acordo com a sua essência ou substância e sua realidade econômica, e não meramente sua forma legal.

Neutralidade: As demonstrações contábeis devem ser neutras, livres de preconceitos, não devendo influenciar nas tomadas de decisões afim de atingir um resultado predeterminado.

Prudência: Consiste na inclusão de certa dose de cautela na formulação de estimativas em certas condições de incertezas, no sentido de que os ativos ou receitas sejam superestimados e passivos e despesas não sejam subestimados. A empresa deve manter a neutralidade na avaliação dos ativos, passivos, receitas e despesas, pois se assim não fosse perderia a qualidade da confiabilidade.

Integridade: Refere-se ao fato que a informação deva ser relevante afim de evitar omissões que tornem as demonstrações falsas ou erradas, assim sendo inconfiável e deficiente.

A Resolução do CFC n. ${ }^{\circ}$ 785, de 28 de julho de 1995, em seu inciso 1.4 trata do atributo da Confiabilidade:

1.4 - DA CONFIABILIDADE

1.4.1 - A Confiabilidade é atributo que faz com que o usuário aceite a informação contábil e a utilize como base de decisões, configurando, pois, elemento essencial na relação entre aquele e a própria informação.

1.4.2. A confiabilidade da informação fundamenta-se na veracidade, completeza e pertinência do seu conteúdo.

$\S 1^{\circ} \mathrm{A}$ veracidade exige que as informações contábeis não contenham erros ou vieses, e sejam elaboradas em rigorosa consonância com os Princípios Fundamentais de Contabilidade e as Normas Brasileiras de Contabilidade, 
Revista Eletrônica de Ciência Administrativa (RECADM) - ISSN 1677-7387

Faculdade Cenecista de Campo Largo - Coordenação do Curso de Administração

v. 2, n. 1, maio/2003 - http://revistas.facecla.com.br/index.php/recadm/

e, na ausência de norma específica, com as técnicas e procedimentos respaldados na ciência da Contabilidade, nos limites de certeza e previsão por ela possibilitados.

$\S 2^{\circ} \mathrm{A}$ completeza diz respeito ao fato de a informação compreender todos os elementos relevantes e significativos sobre o que pretende revelar ou divulgar, como transações, previsões, análises, demonstrações, juízos ou outros elementos.

$\S 3^{\circ} \mathrm{A}$ pertinência requer que seu conteúdo esteja de acordo com a respectiva denominação ou título.

Torna-se indispensável que a informação contábil seja expressa à luz da verdade, sem erros e não sendo tendenciosa, ela deve ser expressa de acordo com os princípios fundamentais de contabilidade para que estejam livres de qualquer tipo de omissão que tornem as demonstrações Contábeis erradas ou enganosas.

Cabe ressaltar que a informação não pode perder a credibilidade, pois se assim o for, perderá a confiança das pessoas que delas se utiliza, ficando assim desacreditada e sem qualidade para atender a necessidade do usuário.

Por exemplo, o caso Eron e a empresa americana de auditoria Arthur Andersen, conforme VEJA, n. ${ }^{01737, ~} 6$ jun.2002:

A derrocada da Enron abalou o conceito de que as regras do jogo são as mesmas para todo mundo, e que sempre haverá um auditor para garantir isso. A Enron escondia dívidas e turbinava lucros em associação criminosa, segundo alegam os processos de acionistas lesados, com os auditores da Arthur Andersen (...).

Desde que foi envolvida com o colapso da Enron, a empresa de auditoria Arthur Andersen perdeu diversos clientes de prestígio e passou a enfrentar a desconfiança dos parceiros que restaram passando por uma enorme crise de credibilidade, por causa do escândalo, a Andersen teria perdido mais de 30 clientes, que em conjunto rendiam um faturamento de US\$100 milhões por ano.

Destaca-se a importância da confiança tanto das informações contábeis, como do profissional que elas evidenciam, pois a partir do momento que a credibilidade é abalada, a confiança no serviço prestado não será a mesma.

\section{2-Relevância}

De acordo com o IASB (1998, p. 35) "A fim de ser útil, a informação precisa ser relevante para as necessidades de tomada de decisão dos usuários. A informação possui a qualidade da relevância quando influencia as decisões econômicas dos usuários ajudando-os a avaliar eventos passados, presentes ou futuros ou confirmando ou corrigindo suas avaliações anteriores".

Conforme HORNGREN (1978, p. 1004)

As decisões consistem realmente na escolha entre os cursos alternativos de ação que têm conseqüências futuras, as quais geralmente são incertas. Pode-se diminuir os efeitos adversos desta incerteza, tornando-se bem informado sobre o assunto relacionado à decisão. Quanto mais informações relevantes sobre o assunto de uma decisão forem acumuladas, mais claro será o curso de ação correto.

Conforme o IASB (1998, p.36) "A relevância das informações é afetada pela sua natureza e materialidade. Em alguns casos, a natureza das informações, por si só, é suficiente para determinar a sua relevância".

A informação destina-se a retratar um determinado elemento da empresa, independente dos resultados atingidos. A materialidade vai determinar o que 0 contador vai informar em seus relatórios, pois há determinadas informações contábeis cujo custo para evidenciá-las é maior que o benefício que trará aos usuários da informações. A relevância está diretamente relacionada com a tempestividade tratada pelo CFC. 
Revista Eletrônica de Ciência Administrativa (RECADM) - ISSN 1677-7387

Faculdade Cenecista de Campo Largo - Coordenação do Curso de Administração

v. 2, n. 1, maio/2003 - http://revistas.facecla.com.br/index.php/recadm/

\section{3-Tempestividade}

A Resolução do CFC n. ${ }^{\circ} 785$, de 28 de julho de 1995, em seu inciso 1.5 trata do atributo da Tempestividade:

\section{5 - DA TEMPESTIVIDADE}

1.5.1 - A tempestividade refere-se ao fato de a informação contábil deve chegar ao conhecimento do usuário em tempo hábil, a fim de que este possa utiliza-la para seus fins.

1.5.2 - Nas informações preparadas e divulgadas sistematicamente, como as demonstrações contábeis, a periodicidade deve ser mantida.

Parágrafo Único. Quando por qualquer motivo, inclusive de natureza legal, a periodicidade for alterada, o fato e sua razões devem ser divulgados junto com a própria informação.

Para que a informação seja usada adequadamente pelo usuário, faz-se necessário que está chegue em tempo hábil, ou seja, de nada adianta informação atrasada, é preciso ter as informações oportunas na hora certa, afim de que seja otimizado o processo decisório.

Deve-se manter também uma periodicidade das informações e relatórios apresentados, para que a empresa consiga fazer uma avaliação entre os resultados atingidos no passado com os obtidos no momento atual, fazendo parâmetros entre os períodos e acompanhar a evolução da empresa.

\section{4-Compreensibilidade}

Segundo o IASB (1998, p. 35) "Uma qualidade essencial é que as informações apresentadas nas demonstrações contábeis é que elas sejam prontamente entendidas pelos usuários. Para esse fim presume-se que os usuários tenham conhecimento razoável do negócio, atividades econômicas e contabilidade"

Todavia as informações sobre assuntos complexos devem ser incluídas nas demonstrações contábeis, por causa da sua relevância na tomada de decisão pelos usuários .

A informação contábil deve ser evidenciada afim de possibilitar aos diferentes tipos de usuários o seu fácil entendimento, mas sempre retratando de maneira completa as variadas operações da empresa. É necessário que o usuário da informação tenha conhecimento de seus negócios, bem como conhecimento de contabilidade, conhecimento esse que possibilite a compreensão das informações apresentadas.

A Resolução do CFC n. ${ }^{\circ}$ 785, de 28 de julho de 1995, em seu inciso 164 trata do atributo da Compreensibilidade:

$$
\begin{aligned}
& \text { 1.6 - DA COMPREENSIBILIDADE } \\
& 1.6 .1-A \text { informação contábil deve ser exposta na forma mais } \\
& \text { compreensível ao usuário a que se destine. } \\
& \S 1^{\circ} \text { A compreensibilidade presume que o usuário disponha de } \\
& \text { conhecimentos de Contabilidade e dos negócios e atividades da entidade, } \\
& \text { em nível que o habilite ao entendimento das informações colocadas à sua } \\
& \text { disposição, desde que se proponha analisa-las, pelo tempo e com a } \\
& \text { profundidade necessários. } \\
& \S 2^{\circ} \text { A eventual dificuldade ou mesmo impossibilidade de entendimento } \\
& \text { suficiente das informações contábeis por algum usuário, jamais será motivo } \\
& \text { para a sua não-divulgação. } \\
& 1.6 .2 \text { - A compreensibilidade concerne à clareza e objetividade com que a } \\
& \text { informação contábil é divulgada, abrangendo desde elementos de natureza } \\
& \text { formal, como a organização espacial e recursos gráficos empregados, até a } \\
& \text { redação e técnica de exposição utilizadas. } \\
& \S 1^{\circ} \text { A organização espacial, os recursos gráficos e as técnicas de } \\
& \text { exposição devem promover o entendimento integral da informação contábil, }
\end{aligned}
$$


Revista Eletrônica de Ciência Administrativa (RECADM) - ISSN 1677-7387

Faculdade Cenecista de Campo Largo - Coordenação do Curso de Administração

v. 2, n. 1, maio/2003 - http://revistas.facecla.com.br/index.php/recadm/

sobrepondo-se, pois, a quaisquer outros elementos, inclusive de natureza estética.

$\S 2^{\circ}$ As informações contábeis devem ser expressas no idioma nacional, sendo admitido o uso de palavras em língua estrangeira somente no caso de manifesta inexistência de palavra com significado idêntico na língua portuguesa.

A contabilidade deve dispor de informações compreensivas para o usuário, nesse caso, a forma de evidenciação torna-se fator de excelência para uma comunicação eficaz entre as partes.

\section{5-Comparabilidade}

De acordo com IASB (1998, p. 37) "Os usuários devem comparar as demonstrações contábeis de uma empresa ao longo do tempo a fim de identificar tendências na sua própria posição financeira e no seu desempenho. Os usuários devem também ser capazes de comparar as demonstrações contábeis de diferentes empresas a fim de avaliar em termos relativos, a sua posição financeira".

Afim de que se possa fazer avaliações, deve-se fazer um parâmetro ao decorrer dos períodos, da sua própria posição financeira com outras empresas do mercado concorrente. A empresa precisa conhecer suas políticas contábeis juntamente com a elaboração das demonstrações contábeis seguido da observância dos princípios e normas brasileiras de contabilidade.

A Resolução do CFC n. ${ }^{\circ}$ 785, de 28 de julho de 1995, em seu inciso 1.7 trata do atributo da Comparabilidade:

\section{7 - DA COMPARABILIDADE}

1.7.1 - A comparabilidade deve possibilitar ao usuário o conhecimento da evolução entre determinada informação ao longo do tempo, numa mesma Entidade ou em diversas Entidades, ou a situação destas num momento dado, com vista a possibilitar-se o conhecimento das suas posições relativas.

1.7.2 - A concretização da comparabilidade depende da conservação dos aspectos substantivos e formais das informações.

Parágrafo único. A manutenção da comparabilidade não deverá constituir elemento impeditivo da evolução qualitativa da informação contábil.

De acordo com este atributo o usuário poderá acompanhar a evolução da informação através de um determinado período de tempo, seja de uma ou mais entidades. Uma informação que não pode ser comparada com algum parâmetro perde em qualidade.

O contador deve considerar a importância das características qualitativas no seu dia-a-dia para a prestação dos serviços contábeis, até como forma de se manter no mercado.

\section{4-QUALIDADE TOTAL}

A qualidade serve como um instrumento de avaliação para as pessoas, bem como para aprovação ou desaprovação dos produtos ou serviços, mas seu entendimento não se limita apenas a um conceito, mas uma visão global do processo como um todo.

Conforme PALADINI (1995, p. 31) "Qualidade sempre foi um termo de domínio público. Talvez por isso seu conceito foi alterando-se, num processo muito similar ao que ocorre com as palavras de uso comum".

Com isso seu conceito foi se modificando ao longo dos tempos, de acordo com as prioridades de cada época. O conceito da qualidade hoje resulta das próprias transformações econômicas, políticas e culturas das civilizações. 
Segue PALADINI (1995, p.33-37) $\mathrm{Na}$ idade média surgiram os primeiros operadores de controle da qualidade, surgidos a partir do crescimento das pequenas empresas e da diversificação das linhas de produção. São definidos nesse período padrões rudimentares da qualidade para bens e serviços e níveis básicos de desempenho da mão-de-obra. Tendo sido determinadas as condições gerais para o trabalho humano, a característica básica da indústria da época era sua formação a partir de indivíduos ou pequenos grupos de pessoas, que produziam bens e serviços e controlavam, eles próprios a qualidade do que faziam, através de uma única pessoa, um operador ou inspetor.

Com o advento da industrialização, com o crescimento das organizações industriais e o desenvolvimento tecnológico resultaram no aparecimento de supervisores de controle da qualidade. Com a evolução natural dos processos de inspeção foram criados os primeiros conceitos e modelos de inspeção por amostragem, o procedimentos de controle e inspeção geraram a necessidade de estruturação formal e qualificação de pessoal.

Após a segunda guerra mundial o Japão introduziu a qualidade como uma questão cultural relacionando-a com a qualidade de vida dos japoneses, depois de terem fixado o conceito a nível de sociedade, tornou-se mais fácil introduzir as noções e técnicas no interior dos sistemas produtivos.

A descoberta da qualidade por parte do Japão permitiu a popularização dos métodos e da essência conceitual do controle da qualidade, a partir sobretudo, dos trabalhos de Deming e Juran em 1955, como também de Ishikama, que introduziu as técnicas de controle dos processos.

A partir da década de 60 surgiu a estruturação do conceito de controle da qualidade total através do programa zero defeitos nos Estados Unidos estruturado por Armad Feigebaun e o conceito de círculos da qualidade que seria o zero defeito do Japão apesar de muito diverso similar americano, sendo este criado pelo Japonês Kaoru Ishikawa.

A qualidade foi um processo evolutivo ao longo dos tempos, estruturando a partir da década se 60 e alcançando seu auge na década de 80, onde as empresas começaram a refletir sobre a implantação da qualidade como forma efetiva nos processos produtivos.

Ainda conforme PALADINI (1995, p37) "Armand V. Feigebaun foi o criador da expressão qualidade total, considera que a qualidade total deve ser a principal forma de administrar uma organização, envolvendo todos os níveis da empresa".

A qualidade se faz por intermédio de cada trabalhador consciente do seu papel a cumprir. Do comprometimento com o sucesso do negócio em questão, são as pessoas que fazem com que os serviços sejam diferenciados pelo atendimento prestado ao cliente.

Para se obter a qualidade é preciso criar um ambiente especial na empresa onde a excelência do serviço oferecido ao cliente seja missão de todos os membros integrantes da organização, trabalhadores, administradores e gerentes.

De acordo com CAMPOS (1992, p.2) Qualidade "É aquele produto ou serviço que atende perfeitamente, de forma confiável, de forma acessível, de forma segura e no tempo certo às necessidades do cliente".

Em relação ao que o autor expõe torna-se necessário que se encontre um ponto de equilibrio que satisfaça o seu cliente, ou seja, que gere informações confiáveis e com credibilidade, mantendo a pontualidade dos serviços, gerando a informação em tempo hábil e com honorários justos pelo bom serviço prestado. 
Revista Eletrônica de Ciência Administrativa (RECADM) - ISSN 1677-7387

Faculdade Cenecista de Campo Largo - Coordenação do Curso de Administração

v. 2, n. 1, maio/2003 - http://revistas.facecla.com.br/index.php/recadm/

Conforme CAMPOS (1992, p.11) "O objetivo principal de uma empresa (sua sobrevivência através das necessidades das pessoas) pode ser atingindo pela prática do Controle da Qualidade Total".

Mostra-se na tabela abaixo o objetivo das empresas, através de uma visão humanística preocupando-se com todas as pessoas atingidas por sua existência.

Tabela 2 - Objetivos das Empresas

\begin{tabular}{|c|c|c|}
\hline \multirow{5}{*}{$\begin{array}{c}\text { OBJETIVO } \\
\text { PRINCIPAL } \\
\text { Satisfação das } \\
\text { Necessidades das } \\
\text { Pessoas }\end{array}$} & PESSOAS & MEIOS \\
\hline & CONSUMIDORES & Qualidade \\
\hline & EMPREGADOS & Crescimento do ser humano \\
\hline & ACIONISTAS & Produtividade \\
\hline & VIZINHOS & Contribuição social \\
\hline
\end{tabular}

FONTE: CAMPOS, Vicente Falconi, TQC: Controle da Qualidade Total (no estilo

japonês). Belo Horizonte: Fundação Christiano Ottoni, 1992. p.13

O TQC (Total Quality Control) tem como premissa básica atender as necessidades humanas, para isto, é necessário estabelecer padrões de qualidade afim de que as mesmas se tornem reais, sendo para isto, torna-se necessário o contínuo desenvolvimento e aperfeiçoamento desses padrões.

Segundo o autor, o TQC usado como abordagem gerencial nas empresas consiste em criar condições internas que garantam a sobrevivência das organizações a longo prazo.

Em qualquer tipo de empresa o cliente deve estar em primeiro lugar, nas empresas prestadoras de serviços contábeis não pode ser diferente, pois é através dos clientes que as mesmas alcançam seus objetivos, A preferência do consumidor pelo seu serviço em relação ao do concorrente é que garantirá a sua sobrevivência, tornando-se necessário a busca da qualidade, caso contrário a empresa não sobreviverá nos dias de hoje.

\section{5- FUNÇÃO DA QUALIDADE}

A qualidade começa a ser direcionada nos processos das organizações, a partir do momento que se verifica a priori as necessidades dos clientes, planejando ações de melhoria contínua para melhor atendê-los.

JURAN apud PALADINI (1995, p. 44) define função da qualidade como sendo "Um conjunto de atividades através das quais se atinge a adequação do produto ou do serviço ao uso, não importando em que parte da organização estas atividades serão executadas".

No contexto organizacional das empresas de serviços contábeis o desenvolvimento de um processo de qualidade tanto é benéfico para o cliente externo, como para os colaboradores internos, pois auxilia 0 ambiente organizacional interno com padrões, normas e procedimentos minimizando a ocorrência de falhas e de retrabalho e otimizando assim o trabalho para o usuário final do serviço prestado.

O processo de implantação da qualidade numa organização depende muito do quanto cada funcionário se dedicar para que este processo dê certo, pois do contrário se não houver uma mobilização total dos colaboradores o processo não terá êxito, ou seja, os objetivos devem ser um ponto em comum, tanto na área operacional, como gerencial. 
De acordo com a abordagem de JURAN, parte-se do pressuposto que 0 processo da qualidade se torna eficaz através da colaboração de todos, partindo do dono do escritório até funcionário de baixo escalão, ou seja, dependendo do esforço e da interação de todos.

Segundo KAPLAN \& RIESER (1996, p.34) "Qualidade é uma maneira de gerenciar os negócios da empresa. Aprimoramento da qualidade só pode ser alcançado em uma empresa com a participação de todos".

Conforme CERQUEIRA NETO (1992, p.31-32) A função da qualidade é a integração de cinco elementos que componham a satisfação do cliente:

Qualidade: como sendo um amplo processo para qualquer cliente;

Custos: Gerar custos que o cliente possa pagar;

Atendimento: Cumprir as condições de atendimento negociadas e superar as especificações;

Segurança: Entregar itens seguros para utilização de seus clientes;

Moral: Desenvolver moral na relação contratual, para que o cliente the reconheça como parceiro.

Torna-se um desafio para as pessoas da organização, pois para que a função da qualidade fique claramente definida, é preciso esclarecer as metas dos elementos acima determinados, para fins de controle dos mesmos.

Segundo CERQUEIRA NETO (1992, p.33-34) Os elementos são:

Métodos: Para atingir as metas;

Educação e o treinamento:necessários para catalisar os processos definidos pelos métodos;

Execução: Como a execução de cada etapa vai ser desenvolvida e quais os itens de verificação necessários;

Forma de verificação: Se a execução de cada etapa atingiu, ou não, o especificado. A meta que the corresponde. Ou seja, se os dados obtidos estão de acordo com o planejado.

A sobrevivência das organizações depende diretamente de quão hábil é a organização para reorganizar-se internamente, para mudar hábitos e atitudes das pessoas envolvidas, mudando para comprometê-las com o processo de crescimento do negócio onde elas possam ter a certeza que fazem parte do processo se comprometendo e interagindo entre si produtivamente.

\section{6-QUALIDADE EM SERVIÇOS}

Com o advento da era da informação, as empresas estão percebendo a necessidade de estar constantemente atualizadas. A qualidade da informação se torna indispensável, principalmente como instrumento de gestão e com isso o profissional da contabilidade ganha um novo perfil, pois o que se fazia em termos de informação basicamente era para atender as exigências do "fisco". Hoje as empresas necessitam de informações econômico-financeiras quase que diariamente.

Nas últimas décadas, com a crescente concentração de mão-de-obra no setor de serviços e o aumento progressivo da sua importância na economia mundial, a qualidade passou a ser um fator preponderante. e as empresas de serviços contábeis que adotam a gestão pela qualidade nos seus serviços criam um diferencial em relação aos outros profissionais que não aderiram a este segmento.

A qualidade na prestação do serviço se faz presente quando ela garante a plena satisfação do cliente, para tanto, o serviço deve ser bem feito e ter um preço justo, assim o cliente vai consumi-lo e se tornar divulgador daquele serviço e de sua qualidade. Um serviço bem feito não vai só satisfazer a necessidade do cliente como também garantir a sobrevivência da empresa que o presta e até da própria sociedade. 
Revista Eletrônica de Ciência Administrativa (RECADM) - ISSN 1677-7387

Faculdade Cenecista de Campo Largo - Coordenação do Curso de Administração

Mas de acordo com KAPLAN ( 1996, p. 105-106) O conceito de qualidade, no setor de serviços, é de difícil definição, pois compõe-se de uma série de aspectos incomensuráveis, entre os quais:

"Comportamento: sendo o juízo subjetivo que o cliente faz de alguém;

Tempo: Medido pela pontualidade que entregamos o serviço;

Aspecto: Aparência e apresentação do serviço prestado;

Desempenho: A informação pode ser ou não útil quando estiver na mão do cliente;

Precisão: Tem a ver com o faturamento e acompanhamento."

Conforme o autor os próprios clientes podem não saber o que realmente desejam ou necessitam, com isto a empresa prestadora de serviços tem uma oportunidade e um desafio, encarregando-se de elevar o nível do serviço, superando as expectativas dos clientes com um serviço de qualidade.

Segundo o Serviço Nacional de Aprendizagem Comercial - SENAC (1996, p.15) "Bom padrão de qualidade representa alguma coisa bem feita, bem concebida, bem projetada, bem administrada, que atende as especificações, satisfazendo, assim, produtores, prestadores de serviços e clientes. Qualidade então é a totalidade de características de alguma coisa, que the confere a capacidade de atender as necessidades explícitas ou implícitas".

De acordo com KALKMANN (2002) "paralelamente à satisfação do cliente está a satisfação das necessidades da empresa, tanto do empresário quanto dos funcionários que nela trabalham. Ao buscar a qualidade não devemos dispensar a atenção aos colaboradores, tendo em vista a produtividade e como conseqüência o Lucro".

O funcionário com os quais o cliente interage enquanto o serviço está sendo realizado, exerce importante papel na percepção que o cliente terá da qualidade do serviço. O treinamento e a motivação são fatores importantes para manter 0 funcionário comprometido com a qualidade do serviço.

A tabela a seguir lista algumas categorias importantes de clientes externos, junto com o que as empresas necessitam deles e eles das empresas.

Tabela 3 - Clientes Externos

\begin{tabular}{|c|c|c|}
\hline Categoria & O que precisam de nós & $\begin{array}{c}\text { O que nós precisamos } \\
\text { deles }\end{array}$ \\
\hline Clientes & Produtos com qualidade & Faturamento, respeito \\
\hline Proprietários & Faturamento, estabilidade & Apoio amplo \\
\hline $\begin{array}{l}\text { Meios } \\
\text { comunicação }\end{array}$ & $\begin{array}{l}\text { deHistórias que mereçam ser } \\
\text { contadas }\end{array}$ & Boa imagem \\
\hline Comunidades locais & $\begin{array}{l}\text { Empregos, impostos, boa } \\
\text { função social }\end{array}$ & $\begin{array}{l}\text { Força de trabalho, } \\
\text { serviços } \\
\text { Proteção contra }\end{array}$ \\
\hline Órgãos do governo & Respeito às regras & $\begin{array}{l}\text { competição } \\
\text { desleal, paz e tranqüilidade }\end{array}$ \\
\hline Público geral & \multicolumn{2}{|c|}{$\begin{array}{l}\text { Segurança dos produtos, proteção } \\
\text { proteção ambiental }\end{array}$} \\
\hline
\end{tabular}

FONTE: J. M. Juran. Juran planejando para a Qualidade, 3.ed.São Paulo: Pioneira, 1995. p.10

A qualidade aplicada na área de serviços contábeis, visa a melhoria contínua nos serviços prestados e a satisfação máxima dos clientes. Está melhoria não visa 
somente os só do clientes externos mas também os funcionários, dos órgãos públicos e até da comunidade, procurando dar ênfase na precisão e confiabilidade nas informações concedidas. Usando assim a qualidade como uma ferramenta mercadológica, deverá ser usada para agregar valor aos serviços prestados, diferencial competitivo e para o desenvolvimento da organização contábil.

Por outro lado, as empresas que traçam suas diretrizes exclusivamente para a prestação dos serviços a qualquer custo, sem se preocupar com a qualidade, certamente irá sacrificar a necessidade do cliente e por conseguinte o futuro do próprio empreendimento.

\section{7-A QUALIDADE NA EMPRESA PRESTADORA DE SERVIÇOS CONTÁBEIS}

\section{1-Programa 5 "S"Aplicado ao Escritório de Contabilidade}

De acordo com SILVA (1996, p. 21) , o programa 5 "S" (teve sua origem no Japão a partir da década de 50 e pode-se dizer que é a primeira etapa para implementar a gestão da qualidade total.

Os 5 "S" são as iniciais de cinco palavras japonesas relacionadas com arrumação, interpretadas como senso, que significa apreciar ou julgar .

Segundo VICTORINO (1999, p. 99).Os cinco sensos são:

"Seiri: Senso de utilização/organização

Seiton: Senso de arrumação/ordem

Seiso: Senso de limpeza

Seiketsu: Senso de saúde/conservação

Shitsuke: Senso de disciplina consciente, autodisciplina"

O principal objetivo dos 5S é criar um ambiente digno de trabalho, onde o homem possa sentir-se bem no seu local de trabalho, consigo próprio e com aqueles que o rodeiam.

Conforme RIBEIRO (1995, p. 02)

Com a presença dos $5 \mathrm{~S}$ nas diversas atividades do trabalho, outros objetivos são atingidos tais como: melhoria na qualidade, prevenção de acidentes, melhoria da produtividade, redução de custos, conservação de energia, prevenção quanto a parada por quebras, melhoria da atmosfera e ambiente de trabalho, exercício da administração participativa, incentivo à criatividade melhoria do moral dos empregados.

Estes objetivos devem ser estabelecidos pela alta administração, com metas mensuráveis, para serem acompanhadas e avaliadas por todos os colaboradores.

Os 5 "S", indiretamente, por dar a todos oportunidade de opinar, ajudar a introduzir a gestão participativa. Assim, evidencia-se que os 5 "S" são base de todos os outros programas da empresa, visando a qualidade total.

VICTORINO (1997, p. 99 -104) define os sensos da seguinte forma:

Seiri: significa senso de utilização, consiste em identificar somente o que se faz necessário no local de trabalho, manter somente objetos e informações estritamente úteis, e descartar o que não apresenta utilidade e eliminar o que é supérfluo.

Para aplicar o senso de utilização, eliminar tudo o que é desnecessário,

Seguir um fluxograma, previamente definido para as ações de curto prazo;

Persistir na educação a longo prazo;

Promover uma grande limpeza inicial.

Benefícios:

Liberação de espaço;

Reaproveitamento de recursos;

Relocação de pessoal; 
Combate a burocracia;

Diminuição de custos.

Colocando em prática este senso o escritório de contabilidade irá dispor de mais espaço pela eliminação dos objetos em desuso, identificando e remanejamento os recursos que são úteis, procurando eliminar tarefas desnecessárias e desperdícios de materiais, incluindo uma utilização correta dos equipamentos para um aumento do tempo de vida destes.

Seiton: significa senso de arrumação, ou seja, organizar, colocar as coisas em ordem, tudo deve estar no lugar certo e de fácil acesso as pessoas.

Para se aplicar o senso de arrumação deve-se começar guardando os itens de acordo com freqüência de uso, padronizar nomenclaturas, ajustar layout ao fluxo das informações.

\section{Benefícios:}

Economia de tempo;

Diminuição do cansaço por movimentação desnecessária;

Redução de duplicidade de formulários, materiais de expediente, etc.

Com a aplicação do senso de arrumação os objetos e documentos estarão dispostos de maneira a facilitar o acesso, mantendo a aparência de lugar organizado.

Seiso: que quer dizer senso de limpeza, manter limpo o ambiente de trabalho e os equipamentos.

Deve-se aplicar este senso as pessoas devem estar conscientizadas que melhor do que limpar é não sujar.

Educar para não sujar;

Definir responsabilidade para cada área e criar tabela de rodízio de limpeza;

Definir pontos que mereçam maior atenção;

Eliminar a causa da sujeira.

\section{Benefícios:}

Bem-estar pessoal;

Redução de custo da manutenção dos equipamentos;

Prevenção de acidentes;

Boa impressão aos clientes.

O escritório deve estar sempre limpo, de maneira a proporcionar um ambiente agradável que deixe os funcionários, clientes e qualquer visita bem acomodada, pois um local bem limpo e arrumado deixa o cliente impressionado e atraído por este ambiente e principalmente cria um senso do fazer bem feito pelo funcionário.

Seiketsu: significa sendo de saúde, preocupar-se , cuidar e manter todas as condições de trabalho favoráveis à saúde física e mental.

Para que este senso seja implantado é preciso que:

Ter os três primeiros S's implantados;

Eliminar as fontes de perigo;

Promover o embelezamento do local de trabalho;

Difundir material educativo sobre saúde em geral;

Manter excelentes condições de higiene na unidade(cozinhas, banheiros, pátios etc...);

Promover durante o período de trabalho atividades rápidas para restauração do equilíbrio físico, metal e emociona 
Revista Eletrônica de Ciência Administrativa (RECADM) - ISSN 1677-7387

Faculdade Cenecista de Campo Largo - Coordenação do Curso de Administração

v. 2, n. 1, maio/2003 - http://revistas.facecla.com.br/index.php/recadm/

\section{Benefícios:}

local de trabalho agradável;

ausência de acidentes;

economia em combate a doenças (enfoque de prevenção);

empregados saudáveis e bem dispostos.

Para que se tenha um bom ambiente de trabalho, é preciso primeiramente que os colaboradores estejam bem física e mentalmente, deve ser observado a iluminação, climatização, a higiene e apresentação dos colaboradores, promover ação preventiva de atividades práticas em relação a saúde. Esse senso está diretamente relacionado com a vontade de trabalhar.

Shitsuke: Significa senso de disciplina consciente ou autodisciplina, desenvolvimento e manutenção da disciplina e do profissionalismo no ambiente de trabalho.

Para a realização deste senso deve-se fazer naturalmente a coisa certa, ter os colaboradores comprometidos com o cumprimento rigoroso dos padrões éticos, morais e técnicos, e com a melhoria contínua pessoal e organizacional.

compartilhar visões e valores;

dar recompensa material e moral;

educar para criatividade;

ter padrões simples;

melhorar as comunicações em geral;

treinar com paciência e persistência.

Benefícios:

previsibilidade dos resultados;

auto-inspeção e autocontrole;

melhoria contínua a nível pessoal e organizacional (da equipe)

cumprir horários e prazos estabelecidos.

$O$ senso da autodisciplina desenvolve nos colaboradores 0 comprometimento total com a má qualidade, pois desperta a importância do trabalho em equipe como um todo e desperta a responsabilidade sobre as tarefas, valorizando cada funcionário com as suas potencialidades, preparando dessa maneira o ambiente para a implantação de um programa de qualidade total.

O Programa 5 " $S$ " traz benefícios tanto para o individuo como para a empresa, pois eleva o moral do funcionário numa administração participativa para que o programa dê certo $e$, quanto a empresa reduz $o$ desperdício e conseqüentemente seus custos.

CARRADORE, LIVRAMENTO \& LUCKMAN (2000, p.49) propõe um exemplo de folha de verificação do 5 "S" para escritório:

Tabela 4 - Folha de Verificação 5 "S"

\section{Organização}

Descarte de objetos sem serventia alguma

Porte de objetos de uso pessoal necessários no local

Guarda de objetos não utilizados para determinado trabalho

Informações e dados atualizados

Mesa organizada, com quantidade mínima de objetos, somente para uso imediato

Ordenação

Existência de local determinado para cada objeto ou documento 
Revista Eletrônica de Ciência Administrativa (RECADM) - ISSN 1677-7387

Faculdade Cenecista de Campo Largo - Coordenação do Curso de Administração

v. 2, n. 1, maio/2003 - http://revistas.facecla.com.br/index.php/recadm/

Existência de critérios de classificação para a guarda de objetos e documentos Identificação dos corredores, passagens e áreas

Mesas, arquivos, e prateleiras ordenados

\section{Limpeza}

Mesas e cadeiras limpas diariamente

Equipamentos limpos ao início e término do trabalho

Tarefas de limpeza distribuídas para cada funcionário

Cinzeiros limpos ao final do expediente

Limpeza diária do chão

\section{Conservação}

Ventilação adequada nas salas

Inexistência de pó e sujeiras nas salas, atrás de mesas e armários

Áreas comuns limpas

Salas de recepção adequadamente limpas

Preocupação dos funcionários com a própria saúde (física, mental e emocional)

Aspecto geral do ambiente de trabalho agradável

\section{Disciplina}

Uso de uniforme nos empregados

Honorários de reuniões cumpridos à risca

Telefone utilizado adequadamente

Preparação adequada antes de sair do escritório

Documentos confidenciais utilizados apenas por empregados autorizados

Motivação e preocupação com a melhoria contínua do local de trabalho

FONTE: CARRADORE, A. J.; LIVRAMENTO,A. do; LUCKMAN,A .Gestão da Qualidade.

Florianópolis:

Senai -SC,

2000.

\section{2-Normatização ISO 9000}

Em uma economia globalizada em busca de excelência, depara-se com algumas realidades, com as quais os empresários em busca de sua sobrevivência, têm que conviver:

A explosão tecnológica, onde todos estão sendo obrigados a aprender cada vez mais e com rapidez;

Leis de Proteção ao Consumidor mais rígidas;

Os produtos e serviços têm ciclos de vida cada vez menores, tornando o consumidor mais crítico e exigente;

Torna-se necessário que as empresas adotem algum modelo de gestão pela qualidade, visando atender cada vez melhor as necessidades dos clientes, haja visto, que um dos principais objetivos da empresa é a satisfação dos mesmos.

Conforme CARRADORE, LIVRAMENTO \& LUCKMAN (2000, p.85), "A entidade ISO (International Organization for Standarrization) foi criada em 23 de fevereiro de 1947, em genebra, Suíça e cerca de 102 países estão envolvidos e representados nesta Organização, inclusive o Brasil, através da Associação Brasileira de Normas Técnicas (ABNT)".

A série ISO 9000 resulta de um conjunto de normas denominadas: ISO 9000, ISO 9001, ISO 9002, ISO 9003 e ISO 9004 
Revista Eletrônica de Ciência Administrativa (RECADM) - ISSN 1677-7387

Faculdade Cenecista de Campo Largo - Coordenação do Curso de Administração

v. 2, n. 1, maio/2003 - http://revistas.facecla.com.br/index.php/recadm/

Conforme CARRADORE, LIVRAMENTO \& LUCKMAN (2000, p. 89), a ISO 9000, "É que dá as indicações de qual norma ISO se encaixa melhor, de acordo com as características e necessidades de cada empresa" trata das questões contratuais e serve como orientação para as demais normas da série.

De acordo com CARRADORE, LIVRAMENTO \& LUCKMAN (2000) As normas 9001, 9002 e 9003 são normas contratuais, e auxiliam nas relações comerciais entre as empresas

A norma ISO 9004 funciona como um complemento da ISO 9000, servindo para ajudar a descobrir qual modelo deve ser implantado numa determinada empresa.

Conforme SENAC (1996, p.58)

A norma que se aplica a serviços é a NBR ISO 9004-2. Essa norma procura fornecer as diretrizes mais amplas que servem de orientação para as empresas na prestação de serviços. Ela trata de todo o ciclo da qualidade do serviço, desde a identificação das necessidades do cliente até a entrega e a verificação da satisfação deste com o serviço prestado. Internamente, passa por atividades como a especificação e o projeto do serviço e, ao final, volta-se para a prestação do serviço propriamente dito.

As normas ISO foram criadas para normatizar a qualidade servindo como padronização para o mundo e estreitando as relações internacionais. As normas ISO 9000 e 9004 servem de diretrizes e as normas ISO 9001, 9002 e 9003 são normas contratuais, sendo que uma empresa só pode ser certificada em relação às normas contratuais.

O modelo ISO é um modelo de gerenciamento da qualidade e de normas de garantia da mesma no ambiente empresarial. O modelo ISO 9000 é flexível e se adapta aos mais variados tipos de empresas.

Através do certificado as empresas assumem sua capacidade de garantir a qualidade dos produtos e serviços por elas prestados em atendimento aos requisitos de garantia da qualidade determinados pelas normas ISO 9000. É importante destacar que a certificação é da empresa e não do produto, ou seja a garantia da qualidade ISO é do processo produtivo pelos quais os produtos passam.

\section{3-Ciclo PDCA}

O ciclo PDCA é um método de aprimoramento contínuo das tarefas, processos e pessoas, desenvolvido por W. E. Deming e adaptado pelos japoneses, seu objetivo segundo CARRADORE, LIVRAMENTO \& LUCKMAN (2000, p.114) é: qualidade;

"Estabelecer uma diretriz de controle fazendo um planejamento da

Manter o nível de controle respeitando todos os padrões que foram estabelecidos anteriormente;

Alterar a diretriz de controle sempre que necessário para mantê-la atualizada com as necessidades do público-alvo."

O ciclo PDCA é um método de gerenciamento circular e sem fim que permite analisar e melhorar os processos. Este ciclo é formado pelas iniciais de quatro palavras em inglês que significam:
$\mathrm{P}$ (Plan)
Planejar
$\mathrm{D}$ (Do)
Executar
C (Check)
Verificar
A (Action)
Agir

Segundo CAMPOS (1992, p.29) os termos do ciclo PDCA têm o seguinte significado: 
Revista Eletrônica de Ciência Administrativa (RECADM) - ISSN 1677-7387

Faculdade Cenecista de Campo Largo - Coordenação do Curso de Administração

v. 2, n. 1, maio/2003 - http://revistas.facecla.com.br/index.php/recadm/

Planejamento (P) - Consiste em: a) estabelecer metas; b) Estabelecer a maneira (o caminho o método) para atingir as metas propostas.

Execução (D) - Execução das tarefas exatamente como previstas no plano e coleta de dados para verificação do processo. Nesta etapa é essencial o treinamento no trabalho decorrente da fase de planejamento.

Verificação (C) - A partir dos dados coletados na execução, compara-se com o resultado alcançado com a meta planejada.

Atuação corretiva (A) - Está é a etapa onde o usuário detectou desvios e atuará no sentido de fazer correções definitivas, de tal modo que o problema nunca volte a ocorrer.

O ciclo PDCA exerce um importante papel na organização da qualidade, pois a qualidade só é plenamente atingida quando o ciclo gira em todos os setores da empresa, pois significa que todos estão planejando, desempenhando, controlando e agindo corretivamente, ou seja todos são responsáveis pela qualidade do serviço que executam.

De acordo com a trilogia de JURAN planejamento, controle e aprimoramento, apud GRIFO (1994, p.47), "a execução de qualquer tarefa deve ser acompanhada de coleta de dados, de forma a permitir o acompanhamento e comparação dos resultados com os inicialmente esperados, visando ações corretivas que garantam sua manutenção controle e aprimoramento do processo".

Não basta apenas implantar um sistema de qualidade, este deve estar constantemente em manutenção buscando sempre a melhoria dos produtos $e$ serviços, melhorando a qualidade e produtividade e conseqüentemente reduzindo os custos.

\section{8-QUALIDADE NOS ESCRITÓRIOS DE CONTABILIDADE}

Alguns escritórios hoje, já estão preocupados com uma gestão de qualidade, aderindo aos projetos Sistema de gestão pela qualidade ISO 9001:2000 este trabalho pesquisou o Estado do Paraná e Programa PQN/CTC (Projeto Qualidade Necessária - Comprometimento Total com o Cliente) no Estado de Santa Catarina. Para que se tenha uma idéia quanto ao percentual de escritórios que aderiram a estes projetos com relação aos escritórios registrados nos conselhos regionais de contabilidade de cada estado têm-se uma tabela em anexo com o número de escritórios e profissionais de contabilidade registrados nos respectivos CRC.

Projeto Sistema de Gestão pela Qualidade ISO 9001:2000

Quadro 1 - Escritório de Contabilidade Certificados

com ISO 9001:2000

\begin{tabular}{|c|c|}
\hline Região & Número de Escritórios \\
\hline São José dos Pinhais & 01 \\
\hline Toledo & 01 \\
\hline
\end{tabular}

Quadro 2 - Escritório de Contabilidade em Processo de Certificação ISO 9001:2000

\begin{tabular}{|c|c|}
\hline Região & Número de Escritórios \\
\hline Cascavel & 02 \\
\hline Foz do lguaçu & 04 \\
\hline Maringá & 07 \\
\hline Curitiba & 07 \\
\hline
\end{tabular}


Revista Eletrônica de Ciência Administrativa (RECADM) - ISSN 1677-7387

Faculdade Cenecista de Campo Largo - Coordenação do Curso de Administração

v. 2, n. 1, maio/2003 - http://revistas.facecla.com.br/index.php/recadm/

FONTE: SF Assessoria Empresarial, 8 nov. 2002;

Revista FENACON em Serviços, ano VII, n. 82, out. 2002.

Segundo Revista FENACON (outubro/2002) "Todas as empresas em fase de desenvolvimento do programa, período que dura em torno de 12 (doze) meses. Após a fase de preparação, com o cumprimento de todas as etapas do processo de normatização, a empresa participante estará preparada para receber a pré-auditoria, iniciando, assim, sua certificação".

Conforme PIETROBON (2002, p.16)

A implantação de um sistema de gestão qualidade, requer entre outros fatores, tempo disponível e envolvimento - desde a alta direção, passando por todos os níveis operacionais da empresa. A qualidade não é mais um diferencial, mas sim uma necessidade das pequenas e médias empresas dentro do mercado. Em tempos modernos é nossa obrigação tratarmos nossos clientes com a maior qualificação que pudermos.

PQN/CTC (Projeto Qualidade Necessária - Comprometimento Total com o Cliente)

Tabela 5 - Escritórios de Contabilidade em Processo de Certificação PQN/CTC

\begin{tabular}{|c|c|c|c|c|c|c|}
\hline \multicolumn{2}{|r|}{ REGIŌEES } & \multirow{2}{*}{$\begin{array}{c}\text { No } \\
\text { EMPRESAS } \\
15 \\
\end{array}$} & \multirow{2}{*}{$\begin{array}{c}\text { N0 } \\
\text { PARTICIPANTES } \\
150 \\
\end{array}$} & \multirow{2}{*}{ 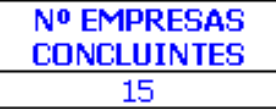 } & \multicolumn{2}{|c|}{ SELO } \\
\hline 1 & Itajaí & & & & 08 & Manutenção \\
\hline 2 & Rio do Sul & 16 & 135 & 13 & 10 & Manutenção \\
\hline 3 & B. Camboriú & 17 & 163 & 17 & 16 & Manutenção \\
\hline 4 & Blumenau & 15 & 252 & 14 & 13 & Manutenção \\
\hline 5 & Fpolis & 15 & 186 & 14 & 13 & Manutençẵo \\
\hline 6 & Joinville & 15 & 209 & 14 & 13 & Manutenção \\
\hline 7 & \begin{tabular}{|l} 
Jaraguá do Sul \\
\end{tabular} & 15 & 210 & 14 & 13 & Manutençẫo \\
\hline 8 & Brusque & 15 & 126 & $\begin{array}{c}\text { Ainda em etapa de } \\
\text { auditoria }\end{array}$ & & 13 \\
\hline 9 & Curitibanos & 13 & 103 & $\begin{array}{c}\text { Ainda em etapa de } \\
\text { auditoria }\end{array}$ & & 94 \\
\hline 10 & Joaçaba & 12 & 120 & 12 & & 11 \\
\hline 11 & Caçador & 11 & 80 & Em andamento & o dia & $03 / 02$ \\
\hline 12 & Lages & 15 & 146 & Em andamento - & odia & $07 / 02$ \\
\hline 13 & $\begin{array}{l}\text { Joinville Turma } \\
02\end{array}$ & 13 & 225 & Em andamento - & o dia & $06 / 02$ \\
\hline 14 & São Bento do Sul & 15 & 150 & Em andamento - & o dia & $07 / 02$ \\
\hline 15 & Fpolis Turma 02 & 13 & 212 & Em andamento - & odia & $08 / 02$ \\
\hline
\end{tabular}

Fonte: www.Fecontesc.com.br

\section{Empresas Certificadas}

Santa Catarina já possui 86 empresas de Serviços Contábeis certificadas com o Selo Catarinense da Qualidade, através do Projeto Qualidade Necessária Programa CTC (Comprometimento Total com o Cliente), O programa visa a implementação de procedimentos organizacionais onde é trabalhado junto aos funcionários conceitos da qualidade e de atendimento ao cliente, métodos de organização utilizando o 5 "S" e padronização de procedimentos, tudo isto para a busca da melhoria continua nos serviços prestados.Em anexo a listagem de empresas no estado de Santa Catarina as quais foram certificadas com o selo da qualidade e sua data de certificação.

Segundo Revista FENACON (julho/2002) "O PQN-CTC vem sendo desenvolvido desde o ano 2000, com o objetivo de orientar as organizações do setor 
Revista Eletrônica de Ciência Administrativa (RECADM) - ISSN 1677-7387

Faculdade Cenecista de Campo Largo - Coordenação do Curso de Administração

v. 2, n. 1, maio/2003 - http://revistas.facecla.com.br/index.php/recadm/

contábil na adoção de posturas criativas para a solução de problemas, execução de tarefas e atendimento ao cliente interno e externo. Dá ênfase para a postura profissional e de equipe, buscando aumento de produtividade, redução de custos e retrabalhos e a satisfação dos clientes".

Conforme KALKMANN (abril/2002) responsável pelo projeto

Explica que as empresas que aderem ao projeto procuram readequar sua gestão, implementando ações referentes aos requisitos da ISO 9000. O PQN-CTC envolve 8 (oito) meses de atividades, incluindo seminários e adoção de vários procedimentos, todos os passos acompanhados por consultores e técnicos. O selo de qualidade tem validade de três anos e as empresas que o recebem abrem suas portas para auditorias de manutenção semestral. $O$ projeto contribui de forma significativa para a verdadeira revolução nos serviços contábeis,com destaque para a modernização de gestão.

\section{CONCLUSÕES}

Está pesquisa se revelou muito importante enquanto instrumento de análise da qualidade dos serviços contábeis prestados pelos escritórios de contabilidade e as práticas adotadas pelos escritórios de contabilidade, chegando as seguintes conclusões:

Teoricamente o ideal é que as organizações de serviços contábeis tivessem como missão gerar informações relevantes para a tomada de decisões, procurando proporcionar confiabilidade nas informações dos relatórios contábeis, transformando os dados neles contidos em informações que sirvam de apoio a tomada de decisão.

Conclui-se a partir deste estudo que o profissional contábil deve ser um parceiro do cliente na gestão da empresa, procurando sempre conhecer o grau de satisfação dos mesmos.

Recomenda-se a implantação de um sistema de qualidade, haja visto, que existem empresas especializadas para suprir está necessidade do contador com programas de qualidade voltados diretamente para escritórios de contabilidade. Inicialmente recomenda-se que os escritórios implantem o programa 5 " $S$ " que estimula a mudança comportamental e organizacional, sendo que é um programa de fácil aceitação pelos funcionários por ser simples sua aplicação, gerando grande resultabilidade no curto prazo, desenvolvendo motivação e o comprometimento para novos programas, melhorar o processo impulsionaria o escritório a sair da estagnação, Tudo isto afim de contribuir na melhoria do atendimento, procurando satisfazer a necessidade do cliente oferecendo serviços diversificados e até personalizados dependendo do cliente, procurando alcançar a excelência e a permanência em um mercado cada vez mais competitivo, sendo que a melhoria do serviço tem que ser gradativa e de forma diária, mesmo com poucos recursos precisa pensar em aplicar modelos de qualidade.

Além da adoção de um sistema de qualidade, é importante a valorização dos funcionários, implantando um processo de aprimoramento contínuo, investindo em inovações tecnológicas e em cursos de aperfeiçoamento para os colaboradores da organização.

Pretendeu-se com este trabalho dar uma contribuição aos profissionais da área contábil, alertando-os para a importância de preocupar-se permanentemente com a qualidade dos serviços prestados, ressaltando a importância em prol dessa qualidade para garantir a sobrevivência da organização no mercado.

Depende de nós contadores saber vender nosso produto e fazer marketing desse produto, para que se possa ser valorizado pelos clientes, mercado e sociedade, gerando assim uma melhor qualidade no serviço. 


\section{BIBLIOGRAFIA}

ABICALAFFE, César. Qualidade Total na Contabilidade. O Contador do Século XXI - O Assessor do Sucesso. [199]

BASTOS, da Rocha Lilia et al. Manual para Elaboração de Projetos e Relatórios de Pesquisa, Teses, Dissertações e Monografias. 4.ed. Rio de Janeiro: LTC,1996. CAMPOS, Falconi Vicente. Controle da Qualidade Total (No Estilo Japonês). 3.ed. Belo Horizonte: Bloch Editores (Rio de janeiro),1992.

CARRADORE, A . J. et al. Gestão da Qualidade. Florianópolis: Senai -SC, 2000. Resolução n. 774 de 16 de dezembro de 1994. Aprova a NBC TI - Das Características da Informação Contábil. Presidente: José Maria Martins Mendes.Conselho Regional do Rio Grande do Sul, Porto Alegre, set.2000.p.101105.

Resolução n. ${ }^{\circ} 785$ de 28 de julho de 1995. Aprova o Apêndice à Resolução sobre os Princípios Fundamentais da Contabilidade. Presidente: José Maria Martins Mendes.Conselho Regional do Rio Grande do Sul, Porto Alegre, set.2000.p.2755.

FRANCO, Hilário.Contabilidade Geral. 21. ed. São Paulo: Atlas, 1983.

GRIFO, Equipe. Iniciando os Conceitos de Qualidade Total. São Paulo: Pioneira, 1994.

HENDRIKSEN, Eldon S.\& BREDA, Michael F. Van. Teoria da Contabilidade. Tradução: Antonio Zoratto Sanvicente. São Paulo : Atlas, 1999.

HORNGREN, Charles T.Contabilidade de Custos. São Paulo: Atlas, 1978.

IASB -International Accounting Standards Board.Normas Internacionais de Contabilidade. Tradução: IBRACON. São Paulo: IBRACON, 1998.

IUDíCIBUS, Sérgio de. \& MARION, José Carlos. Introdução à Teoria da Contabilidade. São Paulo: Atlas, 1999.

IUDíCIBUS, Sérgio de. Teoria da Contabilidade. 5.ed. São Paulo : Atlas, 1997. JURAN, J.M. Planejando para a Qualidade.3.ed. São Paulo: Pioneira,1995.

KALKMANN, Geraldo Luiz. Qualidade Necessária para as Empresas de Serviços Contábeis. Itajaí: Berger, 2002.

KAPLAN, Daniel \& RIESER, Carl. Qualidade Total na Prestação de Serviço: Como Aprimorar as Práticas Gerenciais Adotando a Melhoria Contínua. Tradução: Carmen Youssef. São Paulo: Nobel,1996.Original inglês.

LAKATOS, Ena Maria \& MARCONI, Marina de Andrade. Técnicas de Pesquisa: Planejamento e Execução de Pesquisas, Amostragens e Técnicas de Técnicas de Pesquisa, Elaboração, Análise e Interpretação de Dados. 2.ed. São Paulo: Atlas, 1996.

MARION, José Carlos. Contabilidade Empresarial. 8. ed. São Paulo: Atlas, 1998. CERQUEIRA NETO, Edgard Pedreira de. Gestão da Qualidade Princípios e Métodos.3.ed. São Paulo: Pioneira, 1993.

CERQUEIRA NETO. Paradigmas da Qualidade.Rio de Janeiro: Imagem, 1992.

PALADINI, Edson Pacheco.Gestão da Qualidade no Processo: A Qualidade na Produção de Bens e Serviços. São Paulo: Atlas,1995.

RAUPP, Elena Hahn. Qualidade na Auditoria Interna. Revista Brasileira de Contabilidade. Brasília, n. 122, p.44-53, mar./abr. 2000.

Revista FENACON em Serviços. ano 7, n.76, p.22, abr.2002.

Revista FENACON em Serviços. ano 7, n.79, p.23, jul.2002.

Revista FENACON em Serviços. ano 7, n. 74, p. 26, fev.2002.

Revista FENACON em Serviços. ano 7. n. 82, p.22,out .2002.

RIBEIRO, Jorge Luiz Gonzaga. Apostila curso Programa 5 "S". ano 2002. 
SEVERINO, Joaquim Antônio. Metodologia do Trabalho Científico. 19.ed. São Paulo: Editora Cortez,1993.

SENAC (Serviço Nacional de Aprendizagem Comercial). Qualidade Total em Serviços. 1996.

SILVA, João Martins. O Ambiente da Qualidade na Prática 5S. 3.ed. Belo Horizonte: Fundação Christiano Ottoni, 1996.

VASCONCELOS, Yumara Lúcia. \& VIANA, Aurelina Laurentiva. Evidenciação: Forma e Qualidade. Revista Brasileira de Contabilidade. Brasília, n. 134, p.25-26, mar./abr. 2002.

VICTORINO, Carlos Roberto. Qualidade na Organização e nos Serviços Contábeis: Marketing em Serviços. 1.ed. Santa Catarina: Odorizzi,1999.

www.veja.com.br

www.fecontesc.org.br 